SIR, We were interested to read the case report from McHugh et al. ${ }^{1}$ We have been following up a patient who presented with similar clinical features, but in whom the findings of $\mathrm{T}$ lymphocyte subset analysis of synovial fluid (SF) and peripheral blood (PB) were contrasting (Table 1).

A 51 year old woman presented in August 1983 with generalised lymphadenopathy, fever, weight loss, and arthritis. She was admitted to her local hospital for a lymph node biopsy, which showed features suggestive of angioimmunoblastic lymphadenopathy. When she developed a fever and became anaemic she was transferred to Guy's where a repeat lymph node biopsy showed obliteration of normal lymph node architecture by cells (immunoblasts, plasma cells, and lymphocytes) and vascular components (including cells with endothelial hyperplasia), confirming the diagnosis of angioimmunoblastic lymphadenopathy. Examination at that time showed cervical and axillary lymphadenopathy without hepatosplenomegaly, symmetrical synovitis of metacarpophalangeal and proximal interphalangeal joints, ankles, and knees. Investigations showed haemoglobin $105 \mathrm{~g} / \mathrm{l}$, white blood cell count $11.2 \times 10^{9} / 1$, erythrocyte sedimentation rate $116 \mathrm{~mm} / \mathrm{h}$, direct Coombs' test positive, and a diffuse increase in gammaglobulin (IgG $28 \mathrm{~g} / 1$ (normal 9-18.5)). Rheumatoid factor, antinuclear antibodies, complement, hepatitis B surface antigen, thyroid function, chest $X$ ray, and $X$ ray of joints were all normal. Bone marrow showed a reactive marrow with no specific changes. Multitest (Institute Mierieux, Lyons, France) testing showed anergy, consistent with depressed cellular immune responses.

Clinically the patient responded well to prednisolone ( $20 \mathrm{mg}$ daily) with an increase in haemoglobin and a loss of lymphadenopathy, synovitis, and fever. Joint pain dictated the rate of reduction of steroid dosage, and steroids were stopped in August 1986, since when she has remained well.

Table 1 T lymphocyte subsets

\begin{tabular}{lcc}
\hline & Peripheral blood & Synovial fluid \\
\hline Total WBC $\times 10^{-9} / 1$ & $14 \cdot 2$ & 6.8 \\
Neutrophils $\times 10^{-9} / 1$ & $6 \cdot 1$ & NA \\
Lymphocytes $\times 10^{-9} / 1$ & $3 \cdot 5$ & NA \\
Monocytes $\times 10^{-9} / 1$ & $0 \cdot 3$ & NA \\
& & \\
OKT3 (\%) & $27 \cdot 0$ & 16.5 \\
OKT4 (\%) & $17 \cdot 7$ & 4.5 \\
OKT8 (\%) & 18.0 & $17 \cdot 9$ \\
T4:T8 & 0.98 & 0.25 \\
\hline
\end{tabular}

$\mathrm{NA}=$ not available; $\mathrm{WBC}=$ white blood cell count.
This patient presented in a similar fashion to the onec previously reported. ${ }^{1}$ The response to steroids and the subsequent benign course, however, are in contrast $\frac{\omega}{5}$ Particularly noticeable is the difference in the findings of T lymphocyte subset analysis. Whereas McHugh et abu found a loss of cells of the suppressor phenotype in both PB and SF, these were maintained in the present case and in fact were relatively increased in the SF. Whether this increased number of suppressor cells had an important effect on the outcome of the disease is impossible to assesst from an isolated case. There are, however, theoretica $\overline{\underline{L}}$ grounds for supposing that the numbers of suppressor cellsi at presentation could provide a prognostic guide, and measurement in future cases should allow testing of thisio hypothesis.

Rheumatology Unit,

Division of Medicine,

United Medical and

Dental Schools,

Guy's Hospital,

London SE1 9RT

Reference

1 McHugh N J, Campbell G J, Landreth J J, Laurent $M$ Polyarthritis and angioimmunoblastic lymphadenopathy. $A$ Rheum Dis 1987; 46: 555-8.

\section{Did Galen describe rheumatoid arthritis?}

SIR, There has been a good deal of speculation and: controversy about the antiquity of rheumatoid arthritis. The apparent paucity of convincing descriptions in early. medical publications and the absence of typical rheumatoid 3 erosions in skeletal palaeopathology have led some authors: to speculate that the disease is of recent origin. ${ }^{12}$ Landre-O Beavais is usually credited with the first description of the disorder, written in $1800 . .^{3}$ Others have highlighted the음 difficulties in interpreting either medical accounts of $D$ arthritis or skeletal changes, arguing that the negative evidence cited is of little value. ${ }^{4}$ Recent evidence of RAlike erosions in ancient American populations has led too the suggestion that RA may be a 'New World' disease, like $N$ syphilis, only transmitted to Europe in the 18 th or 19 th centuries. ${ }^{5}$

The Greek physician Galen (AD 128-200) classified joint disease according to its site (e.g., 'podagra', 'sciatica')을 and was the originator of the term 'rheumatism' ${ }^{6} \mathrm{He}$ was $\mathrm{a} \frac{}{\Phi}$ prolific author, writing some 700 books. In his text, 'On the Preservation of Health, he writes about these diseases as follows:

'Now is it not a disgraceful state of affairs that a person市 who has had an excellent constitution should need to be $\frac{\rho}{\mathbb{D}}$ 
carried about by other people owing to gout . . .. Is it not disgraceful that a person should, by reason of that extraordinary thing arthritis, be unable to use his hands and should need somebody else to bring food to his mouth and to perform his toilet necessities for him ..... And even if one overlooks the disgraceful aspect of this, yet one cannot overlook the pain these people suffer, night and day, as though their maladies were torturers twisting them on the rack ..... And the cause of all this must be referred to dissipation or ignorance or both. ${ }^{6}$

Modern rheumatologists may recognise their rheumatoid patients in this powerful description, which clearly separates generalised arthritis from gout. It can obviously be argued that several other arthropathies could result in similar pain and disability, emphasising the difficulty in interpreting early descriptions of arthritic diseases.

Perhaps the most important aspect of this quotation is not in its diagnostic value, or its contribution to the debate on the antiquity of rheumatoid arthritis. Galen appears to be making a political as well as a medical point-'Is it not disgraceful' is a question that remains pertinent today, and should not be purely rhetorical. At the recent 11th European Congress of Rheumatology, held in Athens, this little known quote was highlighted by Professor Bartsocas of Greece and by me. The continuing plight of those with chronic rheumatic disease, the inadequacies of treatment, and relative lack of funding of rheumatology were also addressed at this conference. If Galen had been allowed to return to his home country as a conference delegate what would he have thought of 1800 years of 'progress'? What adjective, other than 'disgraceful' would he have been tempted to use? Would he be accusing us of dissipation, or ignorance, or both?

Department of Medicine, PAUL DIEPPE

Bristol Royal Infirmary,

Bristol BS2 8HW.

\section{References}

1 Buchanan W W, Murdoch R M. Hypothesis: That rheumatoid arthritis will disappear. $J$ Rheumatol 1979; 6: 324-9.

2 Rogers J, Watt I, Dieppe P. Arthritis in Saxon and mediaeval skeletons. Br Med J 1981; 283: 1668-71.

3 Copeman W S C. A short history of gout and the rheumatic diseases. Berkley: University of California Press, 1964.

4 Wood P H N. Is rheumatoid arthritis a recent disease? In: Dumonde D C, ed. Infection and immunology in the rheumatic diseases. Oxford: Blackwell Scientific, 1976.

5 Rothschild B M, Woods R J, Turner K. New World origins of rheumatoid arthritis [Abstract]. Arthritis Rheum 1987; 30 (suppl), Abstract B29.

6 Brock A J. Greek medicine. London: Dent, 1929.

\section{Book reviews}

Outline of Orthopaedics. 10th Edn. Edited by J Crawford Adams. Pp. 490. £11.95. Churchill Livingstone: Edinburgh. 1986.

For 30 years 'Crawford Adams' has been a standard short textbook and has grown in stature with successive editions. The book is written with the wisdom derived from a lifetime's practical experience and a fluency which makes it a delight to read. The illustrations are a model for economy in the presentation of salient facts, and the $x$ ray illustrations are well chosen and very well reproduced. Orthopaedic conditions are presented on a regional basis and of particular value are the tables detailing the essential points of clinical examination and the summaries classifying disorders likely to be encountered in each region. The early chapters dealing with clinical methods and with a general survey of orthopaedic disorders are clearly written, full of interest, and right up to date, but this early promise is not always fulfilled in the later chapters, for example in the application of rational methods of physiotherapy and the use of modern electrophysiological methods in the diagnosis of peripheral nerve lesions. The index is good and typographical errors are few and far between, and those which do occur are unimportant because easily identified. A carefully compiled bibliography arranged under chapter headings. at the end of the book should stimulate reading in greater depth and lead to an appraisal of a number of seminal publications. The soft cover format makes the book ideal for handy reference on the ward or in the outpatient clinic.

Reservations must be expressed about $\mathrm{Mr}$ Crawford Adams' excursions into the field of rheumatology. Nowadays there can be few orthopaedic surgeons who would regard ankylosing spondylitis, gouty arthritis, and rheumatic fever as 'examples of orthopaedic conditions'. The author departs from standard practice by isolating salicylates as 'first line' drugs, designating all the remaining nonsteroidal anti-inflammatory drugs as 'second line' agents, and relegating to a 'third line' category the so-called disease modifying agents such as gold and penicillamine. After more than a decade of successful use in appropriate circumstances it is a little disconcerting to find immunosuppressive drugs described as "being used in trials at some centres but their place is not yet established'. When the pathology of gout is discussed it is stated merely that 'the primary fault is an impaired excretion of uric acid by the kidneys'. Many years ago the reviewer found some inspiration in an early edition of 'Crawford Adams' in a search for understanding of the peculiarities of the shoulder and now it seems a little curious to find no reference to the use of local corticosteroid injection in the management of musculotendinous cuff lesions, while 'uniform limitation of all movements' is hardly the diagnostic hallmark of shoulder capsulitis.

A great deal of the modern orthopaedic surgeon's time is 